\section{Dancing about Architecture} Milan Bulaty
Once when I was at IKEA in Berlin-Tempelhof, I could not take my eyes off the other customers. At first, I took a closer look because I heard many different languages. The customers evidently came from all over the world - they were young and old and every age in between. It also seemed to me that almost all layers of society were represented. I watched friends, couples in love, and families discuss and even argue about the beauty of shelves, sofas, and tables. Everyone wanted to buy tasteful furniture to create an appealing interior for their own home. We all want to spend time in beautiful rooms. It appears to be a universal desire. We feel good in beautiful spaces. Within them, we work better, relax better, and live better. At the same time, the spatial design should serve certain purposes, and the furniture should be appropriately functional. It is easier to agree on the latter than the former. A room is beautiful if we perceive it as such-but what is beautiful for one person is not necessarily so for another. During my philosophy studies I had little to do with aesthetics. I learnt a lot during my library internship, but not how to build a beautiful library. I knew only this: we humans strive for beauty, whether it is in our own appearance, our clothes, or the environments we spend time in. We love beautiful shapes, movements, and fragrances. We take delight in fascinating atmospheres and great sounds. When we talk or write about them, we use comparisons. And we usually fail.

After the building permit and financing for a new central library at the Humboldt University in Berlin had been secured, we had to set out what we actually wanted. At the time, we already had experience with conversions, renovations, and building projects throughout the library system. As such, the task was not an entirely new one-but due to the scale of the building project and its exposed location right by the Friedrichstraße S-Bahn train station, as well as its importance for the university, it was significantly more difficult than previous projects. The library was Humboldt University's first new building after "Die Wende"- the events leading to and including the reunification of Germany-in Berlin-Mitte. Everybody wanted it to represent the alma mater, which had been renewed in many respects. The more I asked around amongst the members of the university, the more impossible the task of bringing together the different ideas and selecting a suitable design from the competition seemed to me.

Back then-at the beginning of the twenty-first century-a lively dispute about the function of libraries was already taking place. The process of digitization was starting, and we could imagine that the library's entire collection might eventually be presented on the Internet, accessible to everyone. Would it not make more sense to use the money for a datacenter and digitization? Would we even need a library building? And a new building at that? I too asked myself these questions. I had been mistaken about future developments several times in my life and had suffered the consequences accordingly. I therefore reckoned on my views potentially being wrong. Even so, I believed this: if we were to build a university library, it had to offer something that cannot be found anywhere else-a big reading room with a unique atmosphere. A room 
where one can read, write, and think at high levels of concentration, while at the same time being part of a community. A room that enables both solitary work and a shared experience. I remembered my own studies in Prague, Freiburg, and Heidelberg. Charmingly old-fashioned reading rooms drifted into my memory; different building styles, charming lighting conditions, and working atmospheres that are difficult to describe but pleasant.

I was able to persuade close colleagues of this during discussions about the concept, and so our public invitation to tender included a requirement for a central reading room. The prize jury finally decided on a design by Max Dudler because the firm offered an original solution for this requirement.

It would be dishonest to conceal the fact that many experts did not agree with our concept and the resulting decisions. As it was not to be built for me personally but for the public, I took criticism and doubts very seriously. In addition, there was the responsibility of justifying a cost of more than 70 million Euros. I did not doubt that the beauty and atmosphere of the new building were the most important objectives, but I was concerned about whether my subjective notions of its beauty and unique atmosphere would be shared by others. On the other hand, there seemed to be a consensus on requirements such as the natural lighting of reading spaces, free access to books and journals, and an overall high-quality interior.

As future users, we discussed important aspects of the new building intensively with Max Dudler and his team, and viewed many other libraries together. The same questions kept coming up: what do we want? What is beautiful? How can an atmosphere be created that everyone-the future visitors, we librarians, and the architects-are satisfied with? I learned not only that many pairs of eyes see more and see differently, and that other perspectives contribute to clearer decisions, but how important it is to have shared aims and convictions. Of course, I also discovered a great deal about architecture and the art of building. When Max Dudler asked me what was beautiful, I faltered. It was easier to point out beauty when we saw it. During viewings throughout Europe, it was easy to agree on what was beautiful and why. We stood in the middle of a library and perceived how symmetry structures a space harmoniously, how indirect light generates a light and buoyant atmosphere, how furniture made of wood facilitates wellbeing. Precisely because of the special silence that reigned in a beautiful old reading room, we could feel a certain pulse there.

I was very impressed with the way the two project managers at the Dudler firm really discussed the whole design for the new library with us. Walls, floors, lighting, shelves, tables, and chairs-the beauty we strove for was developed through many small and large steps. I remember a meeting in which we wanted to decide on the color scheme for the library rooms. The more we talked, the clearer it became how complex and difficult it is to harmonize the coloring of the wooden cladding with that of walls, floors, and furniture. The colors should be different, but also complement each other. They should set accents and highlight 
function. Architects, librarians, and representatives of the university and the senate administration went around and around in circles without reaching a conclusion. Eventually, Max Dudler spoke the decisive words, "Enough of this! We will decide on the color of the wood first, and then we will determine the colors of the other things." And indeed, it went very quickly after that; we agreed on the use of Canadian cherrywood for the wall paneling, and the other necessary decisions also went relatively easily and briskly.

We always communicated with words, even though Max Dudler and his team emphasized more than once that they found it much easier to design good architecture than to talk about it. When I recently encountered the saying "Writing about music is like dancing about architecture" again, I immediately recalled our debates at the time. The idea of dancing about architecture-or rather the (im)possibility of dancing about architecture-appealed to me greatly, and I remembered my very first reaction to the almost-finished, paneled reading room. A few months before the completion of the construction work, I was on holiday and went skiing in the Alps with my wife. Even there, I was concerned about the future beauty of the library, how it would appeal to students, and how it would be received by critical Berlin. The sport and exercise in the cool, clear air made me so tired that I could at least sleep deeply and restoratively. Nevertheless, I was restless and uncertain, and so we went straight to the building site on the day of our return. I wanted to see the progress and was curious about what the impact of the reading terraces inside would be. I still can recall the feeling that overwhelmed me at the time. I saw the empty terraces and their Canadian cherrywood cladding-and I madly leapt up, bouncing around wildly, and I hugged my wife and exclaimed: "We've won!" It was nothing less than an exuberant DANCE of joy-about successful architecture. 